\title{
Correction to: Innovative Technologies and Learning
}

Lisbet Rønningsbakk, Ting-Ting Wu, Frode Eika Sandnes, and Yueh-Min Huang

\section{Correction to: \\ L. Ronningsbakk et al. (Eds.): Innovative Technologies and Learning, LNCS 11937, https://doi.org/10.1007/978-3-030-35343-8}

In Chapter "Visual Attention Analysis During Program Debugging Using Virtual Reality Eye Tracker":

The original version of this chapter was revised. The affiliation of the authors listed the incorrect country. It was corrected to "Taiwan, Republic of China."

In Chapter "A Systematic Literature Review of Qualitative Gamification Studies in Higher Education":

The original version of this chapter was revised. Corrections, which were not incorporated during the proofing stage due to a technical error, were incorporated. These corrections affected citations, references, and an author's affiliation. Typographical errors were also corrected and the email addresses of all authors were added.

The updated version of these chapters can be found at 